Review

\title{
Potential roles of extracellular vesicles in the pathophysiology, diagnosis, and treatment of autoimmune diseases
}

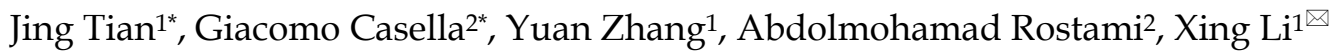 \\ 1. National Engineering Laboratory for Resource Development of Endangered Crude Drugs in Northwest China, Key Laboratory of the Ministry of Education \\ for Medicinal Resources and Natural Pharmaceutical Chemistry, College of Life Sciences, Shaanxi Normal University, Xi'an, Shaanxi 710119, China; \\ 2. Department of Neurology, Thomas Jefferson University, Philadelphia, PA 19107, USA. \\ *These authors contributed equally to this work. \\ $\triangle$ Corresponding author: Xing Li, email: xingli_xian@126.com \\ (C) The author(s). This is an open access article distributed under the terms of the Creative Commons Attribution License (https://creativecommons.org/licenses/by/4.0/). \\ See http:/ /ivyspring.com/terms for full terms and conditions.
}

Received: 2019.09.25; Accepted: 2019.11.22; Published: 2020.01.01

\begin{abstract}
Since extracellular vesicles (EVs) were discovered in 1983 in sheep reticulocytes samples, they have gradually attracted scientific attention and become a topic of great interest in the life sciences field. EVs are small membrane particles, released by virtually every cell that carries a variety of functional molecules. Their main function is to deliver messages to the surrounding area in both physiological and pathological conditions. Initially, they were thought to be either cell debris, signs of cell death, or unspecific structures. However, accumulating evidence support a theory that EVs are a universal mechanism of communication. Thanks to their biological characteristics and functions, EVs are likely to represent a promising strategy for obtaining pathogen information, identifying therapeutic targets and selecting specific biomarkers for a variety of diseases, such as autoimmune diseases.

In this review, we provide a brief overview of recent progress in the study of the biology and functions of EVs. We also discuss their roles in diagnosis and therapy, with particular emphasis on autoimmune diseases.
\end{abstract}

Key words: Extracellular vesicles; autoimmune diseases; biomarkers; communication; therapy.

\section{Introduction}

Extracellular vesicles (EVs) are broadly classified in three sub-classes, depending on their biogenesis and size, exosomes (10-100nm); microvesicles (MVs), also called ectosomes, (100-1000nm); apoptotic bodies $(1000-5000 \mathrm{~nm})$ [1]. However, even if this nomenclature is extensively used, the classification of these heterogeneous populations of EVs is still a matter of debate [2]. Our initial understanding of EVs originated from exosomes found in sheep reticulocytes in 1983 [3]. EVs represent a direct means of cellular communication [1]. They thus play an important role in the development and regulation of many biological processes [4]. They carry proteins,
DNA and various RNAs: mRNAs, miRNAs, long non-coding RNAs (lncRNAs), circular RNAs (circRNAs), all involved in intracellular signal transduction [5]. New research evidence suggests that mitochondria may also be contained in EVs, and that these mitochondria are capable of inducing epigenetic modifications of target cells in target organs, such as mesenchymal stem cells (MSCs) altering the macrophage phenotype by EVs-mediated mitochondrial transfer [6]. To induce an effect, EVs must interact with target cells, either directly with the plasma or with the endosomal membrane after cellular uptake [1]. Thus far, different mechanisms for 
EVs uptake have been proposed [7].

Given that, theoretically, every cell in the body releases EVs and that in pathological conditions their amount may increase, they represent an excellent biomarker for several diseases [5]. In fact, thanks to their properties, EVs can be detected in many different biological fluids such as blood, saliva, urine, semen, bile, cerebrospinal fluid (CSF), amniotic fluid, ascites and breast milk [8-10]. Finally, thanks to their biological characteristics, the idea of using EVs as a therapeutic delivery vehicle in many applications has recently emerged [11]. Indeed, the ability to deliver molecules in different biological districts hardly accessible such as central nervous system (CNS), without showing immunogenicity, candidates EVs as future therapy. So far, several approaches using EVs as therapy have been proposed [12-15], and many of them have shown promising results in animals, giving chances to use them in humans [16]. At present, there are 477 clinical trials underway using EVs in different pathologies according to https://clinicaltrials.gov. We have summarized a portion of the clinical trials related to EVs in Table 1.

\section{The biogenesis of Extracellular Vesicles}

The biogenesis of EVs is similar but not exactly the same [9]. Exosomes are the smallest particles and are mainly composed of ceramide, a lipid produced from sphingosine [1]. Exosomes are formed intracellularly via endocytic invagination (early and late endosomes) and are released into a structure known as the multivesicular body (MVB), resulting in the progressive accumulation of intraluminal vesicles (ILVs) [5]. The MVB can undergo lysosome acidification and destruction or fusion with the plasma membrane, releasing its cargo of exosomes a mechanism regulated by Rab GTPases proteins [17, 18]. Endosomal sorting complexes required for transport (ESCRT) is a mechanism of ILVs or MVB production [19]. ESCRT is a protein complex located on the cytoplasmic side of the endosome; its main function is to sort cell components into ILVs, forming the precursor of the exosomes. ESCRT contains four main complexes (ESCRT-0, I, II, III) and accessory proteins (such as vacuolar protein sorting 4, VPS4; vesicle trafficking 1, VTA1; ALG-2 interacting protein $X$, ALIX), all involved in exosomes biogenesis [20]. The ESCRT complex functions in a certain order. First, ESCRT-0 and ESCRT-I limit the ubiquitinated transmembrane cargo subunits to the micro-domains of MVE or ILVs, while causing deformation of the membrane structure, ESCRT-II is then used to recruit ESCRT-III for the budding and scission of this micro-domain [21, 22]. The classical ESCRT pathway interacts with syntenin and the ESCRT accessory protein ALIX, and bridges the ESCRT-III subunit VPS32, ultimately performing the scission function of the vesicles to form a closed vesicle [21]. The protein of the tetraspanin family is involved in the sorting of vesicle contents [21].

Microvesicles are the EVs class that has been the least studied and thus far we know very little about their biogenesis. They are usually larger than exosomes, depending on the cell type [1]. MVs are released by the direct budding or protrusion of the plasma membrane. They typically originate at the plasma membrane in the region called lipid rafts, which are membrane domains rich in cholesterol and glycosphingolipids [23]. The formation of MVs primarily involves membrane components and the cytoskeleton [9]. Moreover, during MVs formation there is externalization of the phospholipid phosphatidylserine (PS) [24], which normally resides exclusively in the inner layer of the plasma membrane [18].

Table 1. Clinical trials related to EVs.

\begin{tabular}{|c|c|c|c|c|}
\hline Condition or disease & Origen of EVs & Type of EVs & Phase & NCT number \\
\hline Type1 Diabetes Mellitus Type2 Diabetes Islet Cell Transplantation & Blood & EVs & ND & NCT03106246 \\
\hline Smoker & Human broncho alveolar lavages & EVs & ND & NCT03608293 \\
\hline Blood Coagulation Disorders & Bone marrow & EVs & ND & NCT00086476 \\
\hline Bronchopulmonary Dysplasia & Bone marrow mesenchymal stem cell & EVs & Phase 1 & NCT03857841 \\
\hline Coronary Artery Disease Ischaemic Heart Disease Angina Pectoris & Blood & EVs & ND & NCT03674255 \\
\hline Cancer & Blood & EVs & ND & NCT03262311 \\
\hline Cerebrovascular Disorders & Mesenchymal stem cell & Exosomes & Phase 2 & NCT03384433 \\
\hline Ulcer & Plasma & Exosomes & Phase 1 & NCT02565264 \\
\hline Pancreatic Cancer & Venous blood & Exosomes & ND & NCT03821909 \\
\hline Colon Cancer & Plant & Exosomes & Phase 1 & NCT01294072 \\
\hline Sarcoma & Blood & Exosomes & ND & NCT03800121 \\
\hline Lymphoma & Blood & Exosomes & ND & NCT03985696 \\
\hline Cirrhosis & Hepatocyte & MVs & ND & NCT03837444 \\
\hline
\end{tabular}

ND: Not Determined. 
Table 2. Composition of exosomes and microvesicles.

\begin{tabular}{|c|c|c|}
\hline Composition & Exosomes & Microvesicles \\
\hline Proteins & $\begin{array}{l}\text { MVB formation: ALIX, TSG101; Tetraspanins: CD9, CD63, CD81,CD82; } \\
\text { Membrane transport and fusion: annexins, flotillins, GTPases; } \\
\text { Adhesion: integrins; Antigen presentation: MHC class molecules; Heat } \\
\text { shock proteins: HSC70, HSP90; Adaptor protein: Syntenin-1 }\end{array}$ & $\begin{array}{l}\text { Matrix metalloproteinases; Tetraspanins: CD9, CD63; } \\
\text { Glycoproteins: GPIb, GPIIb-IIIa, P-selectin; Integrins: Mac-1; } \\
\text { Receptors: EGFRvIII; Cytoskeletal components: } \beta \text {-actin and } \\
\text { a-actinin-4; Antigen presentation: MHC class molecules; } \\
\text { Heat shock proteins: HSC70, HSP90 }\end{array}$ \\
\hline Lipids & Ceramide; Cholesterol; Phosphatidylserine; Sphingolipids & $\begin{array}{l}\text { Phosphatidylcholine; Sphingomyelin; } \\
\text { Phosphatidylethanolamine; Lysophospholipids }\end{array}$ \\
\hline Nucleic acids & mRNA; miRNA; Non-coding RNA; DNA & mRNA; miRNA; Non-coding RNA; DNA \\
\hline
\end{tabular}

Table 3. The potential protein markers of exosomes and microvesicles.

\begin{tabular}{ll}
\hline & Exosomes \\
\hline Markers & ALIX; TSG101; CD81; Syntenin-1; ADAM 10; EHD-4; Annexin XI \\
Shared markers & Hsc70; Hsp90; Flotillin-1; Annexin II; MHC I; MHC II; CD9; CD63; Actin; Ezrin; Moesin \\
\hline
\end{tabular}

Currently, no protein markers have been identified for distinguishing exosomes and MVs clearly. However, it has been extensively demonstrated that exosomes fractions are enriched by Alix, tumor susceptibility gene 101 (TSG101), CD81, and syntenin- 1 proteins, whereas MVs fractions are enriched by integrins, metalloproteinases, and high levels of PS exposed to the outer membrane leaflet [2, 25]. Hence, the following two tables summarize the differences in composition and potential protein markers for different classes of EVs. Table 3 is based on the work of Kowal J et al., which combines gradient centrifugation with iodixanol gradients to separate different sizes of EVs (light $\mathrm{sEV}$, dense $\mathrm{sEV}$, large EVs) and perform western blot (WB) detection [26]. Dissimilarly, Yusuke $Y$ et al. performed WB detection on the total EVs obtained by ultracentrifugation of 9 different cells, analyzed the abundance of different kinds of conventional protein markers in the cell lysates and corresponding total EVs [27]. The results indicated that CD9 and CD81 are highly enriched in various EVs regardless of the corresponding protein abundance in parent cells. This slightly different result may be due to differences in the methods of extraction and comparison of $\mathrm{WB}$, which also reminds us that various types of EVs need to be standardized protein markers.

As for the release of EVs, a small fraction of EVs will be dissolved in the extracellular fluid with their cargoes, while most of them will interact with specific types of cells. This interaction is not random, but depends on the expression of some specific receptors on the cell surface, although these receptors are not fully identified $[28,29]$. Moreover, the interaction of most EVs with this specific cell occurs not only near the release site, but also at regions far away from it. Through this interaction, a portion of EVs will bind directly to cell surface receptors, while others will activate receptors to trigger intracellular signaling, some that bind to the receptor and fuse with the target cell membrane, and then release the cargo into the cytoplasm; another portion of EVs will enter the cell by reverse extracellular fusion of the target cell membrane, this fusion occurring on the surface or being internalized by endocytosis or phagocytosis. Once endocytosed or phagocytosed, EVs can be degraded and their components captured by cells for their own physiology. When these cargoes are mixed with local molecules, they participate in the production of other EVs that are similarly released or fused to other cells. This process is defined as a recycling of intercellular communication [28-30].

\section{EVs isolation and characterization methods}

In the last few years, many techniques for EVs isolation and characterization have been described in the literature, many of which, however, have not been well standardized [31]. To address this issue, the International Society for Extracellular Vesicles (ISEV) has published a paper on the minimal experimental requirements for definition of EVs and their function (MISEV) [32]. We list below the methods most widely used in EVs experimentation.

Isolation: (1) Ultracentrifugation, including differential centrifugations for isolating different EVs fractions, is by far the primary isolation method in EVs application [31]. It removes cells and debris under low centrifugal force $(300 \times \mathrm{g} \sim 2000 \times \mathrm{g})$ and collects EVs under high centrifugal force $(110000 \times \mathrm{g})$. The disadvantage is that the instrument is expensive, the extraction takes time and effort, and the purity is low. (2) Density gradient is used for isolating different fractions according to their different density. It is a more rigorous method than ultracentrifugation and is usually used to separate exosomes because of its high purity characteristics, but it cannot meet the requirements of large amount of samples [33]. (3) Co-precipitation technique relies on the ability of the customized polymer to co-precipitate EVs at lower 
centrifugation rates $[34,35]$. This method easily causes co-precipitation of non-EVs components and greatly reduces the purity of EVs. Although commercial kits have been developed, they are still not suitable for large-scale use. (4) Size exclusion-chromatography (SEC) takes advantage of the principle of gel chromatography and the EVs are mainly purified by weight or size, it has a high yield but low specificity [34, 35]. Although these methods represent the most suitable ones proposed thus far, there is uncertainty about their application and efficacy in clinic, where the source of EVs samples is very often limited.

The most commonly used method is ultracentrifugation, Ludwig AK et al. combined polyethylene glycol (PEG) co-precipitation and ultracentrifugation to obtain EVs from cell culture supernatants, which can obtain ideal EVs in large quantities without affecting the results of in vivo experiments[36]. This method also optimizes the shortcomings of PEG co-precipitation and has reproducibility and scalability, but the final product still contain several non-EV related molecules, which are less pure than size exclusion chromatography and sucrose density gradient centrifugation. At present, microfluidic filtering techniques are considered the most promising strategies for EVs separation in clinic based on their expandable flux, high degree of automation, and solid reproducibility [34,37]. Liu C et al. introduced a method for EV purification by microfluidic filtering combined with droplet enzyme-linked immunosorbent assay (ELISA), which fills the gap in accurate quantification of EVs [38]. Wu et al. introduced a method based on the acoustic principle combined with microfluidic technology whereby it would become relatively simple to isolate EVs from whole blood, in a label-free and contact-free manner that would protect the peculiarities, structures and functions of isolated EVs [39]. Another novel technique for EVs purification proposed by Kabe et al. [40], consists of a high sensitivity and linearity method from human serum using the properties of magnetic nanobeads and optical disc technology.

Characterization: WB remains by far the common used method for characterizing EVs; also, in this case, the ISEV has published guidelines for the identification of EVs, using antibody for proteins like CD63, CD9, CD81, TSG101, HSP70, Alix [9]. For studying EVs size and morphology, reliable methods are electron microscopy (EM) techniques such as transmission electron microscopy (TEM), scanning electron microscopy (SEM), Cryo-electron microscopy (Cryo-EM), and atomic force microscopy (AFM). Confocal fluorescence microscopy (CFM) is another advantageous technique for studying the interaction between EVs and cells [41-43]. This technique has resulted very convenient to study the internalization of EVs by recipient cells [42-46]. Mrinali et al. developed an innovative method that combines formalin with 1-ethyl-3-(3-dimethyl aminopropyl) carbodiimide (EDC) to improving EV imaging in situ. This approach avoids the traditional formalin-based technique, which may reverse cross-linkage due to temperature and allow EVs to escape from the tissue, resulting in a negative or low signal [47]. Therefore, this technology has dramatically improved EVs studies related to basic science, and perhaps, it will be used for clinical studies. Furthermore, Nanoparticle Tracking Analysis (NTA) and Tunable Resistive Pulse Sensing (TRPS) are common techniques for EVs quantification and size distribution [48]. NTA is able to track the scattering of individual vesicles over time, while TRPS is the change in the instantaneous current when the vesicles pass through the pores $[49,50]$. According to the work of Akers JC et al, exosomes are more suitable for NTA, and MVs is more suitable for TRPS [51]. Flow Cytometry is also a widely use method for characterization and quantification [52], especially now that there is a new fluorescence activated cell sorting machine with a detection limit around $100 \mathrm{~nm}$ (Cytoflex) [34].

\section{EVs as therapy}

Our current knowledge on EVs provides opportunities for their use in therapy. The relevance of EVs as a therapeutic tool, already established in the last few years, is still growing and promising important developments for the near future. Many approaches have already been developed $[5,12,35$, 53-55]. EVs act an important role in the therapeutic effect of MSCs and are therefore considered as a potential alternative to MSCs. Thus, MSC-derived EVs (MSC-EVs) would induce a regulatory response in the function of $\mathrm{T}-, \mathrm{B}_{-}$, and monocyte-derived dendritic cells [56]. In the present work, MSC-EVs have been shown to possess immunomodulatory functions which promote B cell activation, induction of Breg and B cell proliferation was compared to that the whole MSCs [57]. Fujii et al., showed EVs derived from BM-NSCs have potential therapeutic effect on acute graft versus host disease (GVHD) and indicated the EVs probably inhibit the effector T cell induction and kept circulating naïve T cells [58]. However, EV usually does not treat as well as the cell itself, and its biological effects may be affected by the surrounding microenvironment [59]. In this case, Milad et al., found exosomes derived from MSCs stimulated by IFN-Y displayed a superior therapeutic effect compared with native exosomes. This study indicated that MSCs activated by IFN- $\gamma$, which promote 
IFNy-Exo loaded more immunosuppressive cytokine indoleamine 2,3 -dioxygenase (IDO) resulted in peripheral blood mononuclear cells (PBMCs) proliferation disability. Therefore, this "pre-stimulation" of EVs greatly enhances its therapeutic effect and represents a new approach for treatment.

The most intriguing aspect of EVs to have attracted the scientific interest is the possibility of customizing them "ad hoc" [13]. This means loading EVs with different functional molecules simultaneously [60], targeting EVs membrane for increasing tissue and cell targets [61]. We list here the most recent and promising studies published so far. Kamerkar et al. engineered exosomes (named in the paper iExosomes) to specifically target pancreatic cancer cell-associated KRAS mutant genes, delivering RNAi and CD47 on exosomes [55]. Directly specific targeting of KRAS was not possible to achieve before this study. On the other hand, Kumar et al. demonstrated an approach whereby EVs are encapsulated by a $10 \mathrm{~nm}$ thick protective film formed by a supramolecular complex of ferric ions and tannic acid to achieve non-essential EVs loss, and the protective film can be fused with other molecules as targeted delivery while the protective film is also subject to controlled degradation [62]. Longatti et al. published a method for specifically targeting exosomes membrane, with a single-chain variable fragment of antibody [63]. Recently, Jia G et al. demonstrated a method for treating glioma cells, using a click chemistry method to engineer exosomes with neuropilin-1 peptide and load them with curcumin [60]. Similarly, Tian et al. used a strategy for treating murine ischemia targeting exosomes with c(RGDyK) peptide [13].

However, there are still two problems that need to be solved: the methods for loading drugs into EVs cannot guarantee high loading efficiency [64], and, as a therapeutic medium, EVs cannot be targeted to the lesion area very well for therapeutic effects [65]. Thus, improving the EVs loading and delivering efficiency is one aspect that has been reconsidered, due to a discrepancy in the published protocol and data reproducibility [66]. Piffoux et al. published a method for loading EVs using liposomes and showed impressive results [67]. However, the efficacy of this protocol has not been confirmed.

In the diagnosis and treatment of graft-versus-host disease (GVHD), the application of EVs has made more advancement. The EVs isolated from patient serum contains three miRNAs (miR-423, miR-199, miR-93), which may be related to the incidence and severity of GVHD [68]; and the expression of CD146, CD31, and CD140-a on EVs surface, is also closely related to the onset of the disease [69]. Traditional MSCs therapy after replacement with EVs for GVHD also showed ideal results, suggesting that MSCs-derived EVs are potential for cell-free therapy for GVHD [58, 70]. Kordelas L et al. used MSCs-derived EVs instead of MSCs in the patient with GVHD, and the promising results were obtained. MSCs-derived EVs provide a potentially viable method for refractory GVHD [71].

In other diseases, such as cancer, EVs also bring new opportunities for treatment, prevention or diagnosis. Some studies have found that proteins or nucleic acid components in EVs can inhibit tumor development [72], which may be a direct influence or through antigen presentation to immune cells. For example, DCs loaded with exosomes and alphagalactosylceramide can significantly improve the tumor microenvironment of rats bearing gliomas and increase the median survival of rats [73]. In contrast, hepatocellular carcinoma-derived exosomes miR-21 are thought to convert normal hepatic stellate cells to cancer-associated fibroblasts, thereby promoting tumor progression, which may provide new targets for the prevention and treatment of liver cancer [74]. The latest evidence suggests that the ability of EVs to tissue regeneration is equally astonishing. Human perivascular stem cell-derived EVs can mediate bone repair [75], and endothelial cell-derived exosomes can induce angiogenesis in ischemic myocardium [75], MSCs-derived EVs are important mediators of cartilage repair, which will have great application prospects as a therapeutic drug for cartilage regeneration and osteoarthritis [76].

\section{Extracellular vesicles as biomarkers of autoimmune disease}

In the CNS, EVs have been observed in the cerebrospinal fluid, indicating their involvement in many autoimmune diseases, such as multiple sclerosis (MS) [77] and neuromyelitis optica [78]. They may play important roles in several biological processes such as cell-to-cell communication, immune system response, and nerve degeneration [79-81]. In MS, Verderio et al. showed that the number of myeloid EVs was enhanced. These myeloid-derived EVs were considered as diseases marker which separation from plasma and can be used to monitor disease progress $[77,82]$. Similar works were also proved from plasma and serum and indicated EVs could provide useful information for disease diagnosis. However, serum has been questioned as a biomarker recently. The main comment is that PS-positive MVs in serum are consumed during the promotion of coagulation, and the remaining MVs do not reflect overall MVs levels; platelets also release 
MVs after activation in coagulation; what's more, the presence of thrombin will also influence MVs surface proteins [83]. In summary, plasma rather than serum can lead to more convincing results [84].

Urine is another biological fluid commonly used for new biomarkers assess due to the noninvasive collection approach. Recently, the composition of exosomal miRNA was determined by deep sequencing and several stable expression miRNA were confirmed as biomarkers, which has verified the notion of urinary exosomes as a stable source of miRNA biomarkers for renal fibrosis [85]. Thus, EVs may be a novel biomarker that will soon replace biopsies.

There is also evidence that miRNA production and transport are associated with autoimmune diseases, especially MS [86]. EVs contain a large amount of miRNA, which is the main carrier of circulating miRNAs [86], and the EVs content in patients' blood is also different from that of healthy controls [87]. This thus demonstrates that miRNAs in EVs are a potential biomarker for the diagnosis of MS. At the same time, it also sets forth requirements for the standardization of miRNA collection methods. Recently, the results of sequencing the total circulating exosomes transcriptome in patients with relapsing-remitting MS compared with healthy controls also confirmed that exosomal miRNA is very helpful as a biomarker for patients with MS [88]. In the table below, we summarize some of the recent studies on EVs as biomarkers in autoimmune diseases.

\section{EVs play an important role in autoantigen presentation and $\mathbf{T}$ cell modulation}

Given that EVs express peptide-MHC complexes, they may present antigens and activate immune cell-response [16]. EVs, in particular, exosomes, have been investigated in antigen presentation. Exosomes released by antigenpresenting cells (APC) may express class I and II MHC molecules and co-stimulation molecules and thus, theoretically, activate $\mathrm{CD}^{+}$and $\mathrm{CD}^{+}{ }^{+} \mathrm{T}$ lymphocytes [89]. There are three major mechanisms for EVs to participate in autoantigen presentation. EVs participate in autoantigen presentation process involved in autoimmunity is shown in Fig. 1.

Firstly, exosomes might act indirectly from APCs uptaking/stimulation [90]. This mechanism appears more relevant for naïve T cell activation. Eventually, costimulatory molecules expressed by APCs provide a necessary second signal for activating $\mathrm{T}$ lymphocytes.

Secondly, the exosomes can be internalized by APCs and then present antigen to the surface to form a MHC complex [91, 92]. Once internalized by the APCs, the complex peptide/MHC will be exposed to the membrane. Finally, this complex will be involved in Tlymphocytes activation.

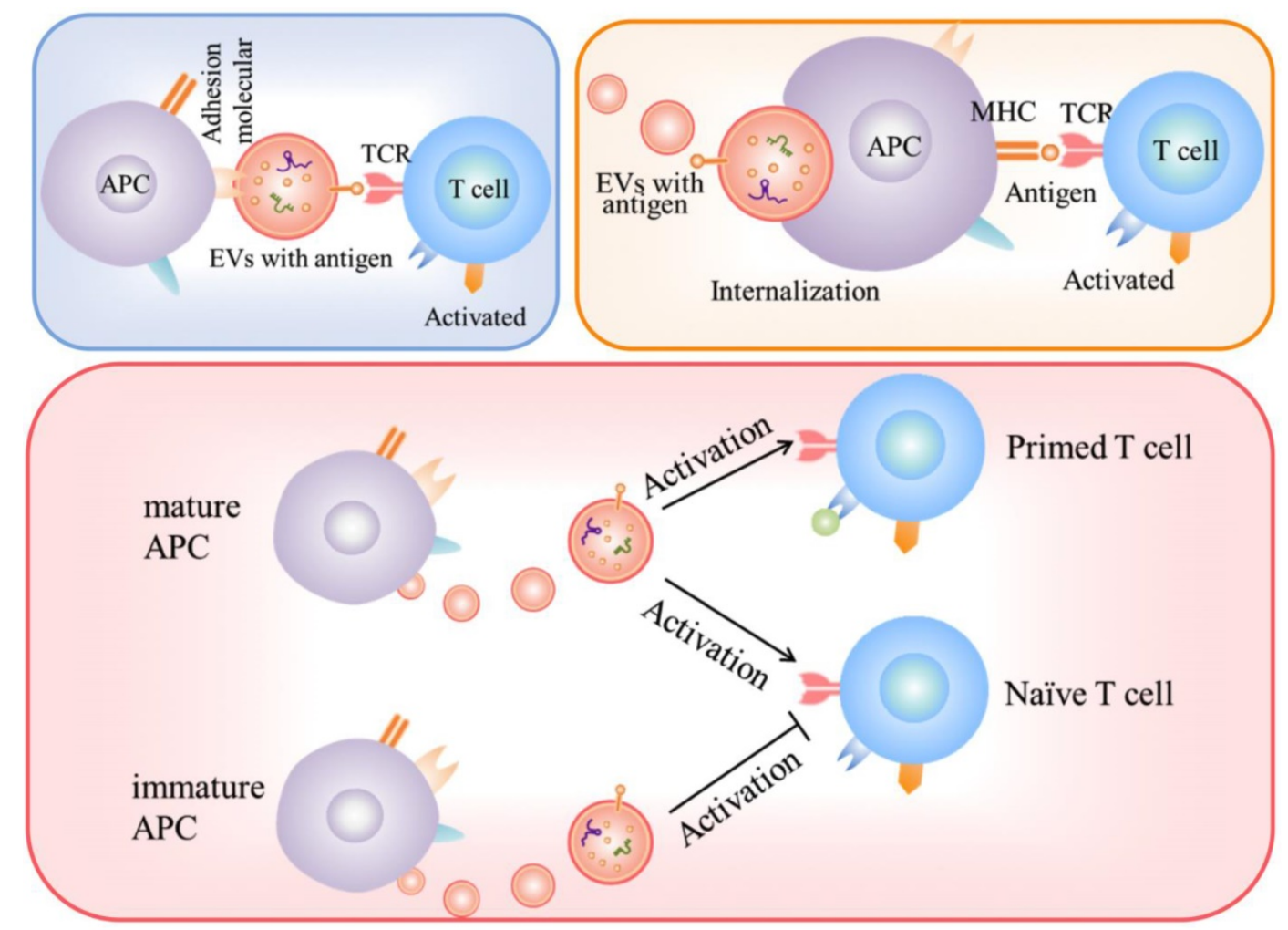

Figure 1. Roles of EVs in autoantigen presentation response. 
Table 4. EVs as a biomarker in autoimmune disease.

\begin{tabular}{|c|c|c|c|c|c|}
\hline EVs Origin & Classification & Components & Change & Disease & Reference \\
\hline Serum & Exosomes & Circulating exosomes & $\uparrow$ & Systemic lupus erythematosus & {$[147]$} \\
\hline Urine & Exosomes & miR-146a & $\uparrow$ & Systemic lupus erythematosus & [148] \\
\hline Urine & Exosomes & miR-29c & $\downarrow$ & Lupus nephritis & {$[85]$} \\
\hline Serum & Exosomes & Total exosomes & $\uparrow$ & Non-obese diabetes & [149] \\
\hline CSF & Microvesicles & Total microvesicles & $\uparrow$ & Multiple sclerosis & [77] \\
\hline Serum & Exosomes & miRNA & $\downarrow$ & Multiple sclerosis & {$[88]$} \\
\hline Serum & Exosomes & Hotair & $\uparrow$ & Rheumatoid arthritis & [150] \\
\hline Synovial fluid & EVs & miR-155 & $\uparrow$ & Rheumatoid arthritis & [115] \\
\hline Saliva & Exosomes & miRNA & / & Sjögren's syndrome & [151] \\
\hline Eosinophils & Exosomes & Total exosomes & $\uparrow$ & Asthma & [152] \\
\hline CFS & Exosomes & Total exosomes & $\uparrow$ & Multiple sclerosis & {$[153]$} \\
\hline $\begin{array}{l}\text { Platelets, total } \\
\text { leukocytes or } \\
\text { monocytes }\end{array}$ & Microparticles & Total microparticles & $\uparrow$ & Multiple sclerosis & [87] \\
\hline Serum & Exosomes & Myelin protein & $\uparrow$ & Multiple sclerosis & [154] \\
\hline Urine & Microparticles & Total microparticles & $\uparrow$ & Type 1 Diabetes & [155] \\
\hline
\end{tabular}

autoantigen presentation response.

Thirdly, the study of the immunostimulatory capacity of APC-derived EVs is still a matter of debate. Some groups have shown that EVs can directly activate T cells [93], while others have shown that EV-dependent $\mathrm{T}$ cells stimulation is not enough and still requires APCs participation [94].

There are few studies on EVs release in T cell immune regulation mechanisms, but some reports have demonstrated its importance. It is noteworthy that regulatory $\mathrm{T}$ cells (Treg)-derived EVs could promote other $\mathrm{T}$ cells polarized to the Treg phenotype [95]. In addition, Treg effectively exocytosed immunosuppressive EVs that suppressed IFN-Y production and the proliferation of Th1 cells [96]. Similarly, EVs from endothelial cells possess the modulation ability which blocks $\mathrm{T}$ cells activation and alleviate chronic inflammation in tissue [97]. In this case, via the transfer of anti-inflammatory miRNAs, MSCs release immunosuppressive exosomes, which are actually used to treat autoimmunity disease in clinical $[98,99]$.

\section{The application of extracellular vesicles in autoimmune diseases}

\section{Multiple Sclerosis (MS)}

MS and its animal model experimental autoimmune encephalomyelitis (EAE) is the most common inflammatory demyelinating disease caused by autoimmune-activated immune cells in the CNS $[100,101]$. It has been reported that EVs can penetrate the blood-brain barrier (BBB) and contribute to brain antigens spreading to the periphery [102]. And the injection of microglia-derived EVs into the CNS of EAE mice enhanced inflammation and exaggerated disease [77]. Moreover, mice with an impaired ability to secrete EVs were resistant to EAE [77]. Therefore, these data indicate that EVs are involved in EAE mechanisms. Based on the EVs roles in EAE and MS, some groups developed treatment strategies that employed the function of exosomes. Exosomes (IFN $\gamma$-Exo) produced by IFN $\gamma$-stimulated MSCs have shown a good therapeutic effect on EAE [103]. These data provided evidence that MSCs-derived exosomes can be used as cell-free therapies for autoimmune and central nervous system diseases. The use of EVs derived from overexpression of TGF- $\beta 1$ dendritic cells to EAE showed that Th1 and Th17 differentiation was inhibited and promoted Treg production, which led to diminished expression of EAE [104]. Casella G. et al. designed a mouse microglial cell line that releases a large amount of engineered EVs containing anti-inflammatory cytokine IL-4, after injection, the clinical score of EAE is significantly reduced [15]. Also, Zhuang et al. delivered curcumin-loaded exosomes through a nasal route to mice with lipopolysaccharide (LPS)-induced encephalitis and reduced neuroinflammation by targeting microglia [14]. In other similar LPS-induced inflammatory demyelinating models, curcumin is also encapsulated by exosomes, playing a role in enhancing anti-inflammatory activity [33]. In short, regardless of small-molecule chemical drugs, nucleotide drugs or protein drugs, as a drug delivery system, EVs have shown great potential for application in modern medicine. Furthermore, Pusic A. D. et al. implied exosomes released from bone marrow-derived dendritic cells as a therapeutic medium that supported the maturation of oligodendrocytes [105]. Dendritic cell-derived exosomes stimulated by low levels of pro-inflammatory factors IFN- $\gamma$ contain higher levels of miR-219, which is vital for oligodendrocyte precursor cells (OPCs) differentiation; meanwhile, these exosomes are proved increase mature oligodendrocytes and recovery the destroyed myelin in vivo. Thus, exosomes 
might not only exacerbate inflammation during EAE but may also induce myelin regeneration.

\section{Rheumatoid Arthritis (RA)}

RA is an autoimmune disease in which the immune system reacts against the body's cells and tissues. Generally, synoviocytes-derived exosomes, in inflammatory conditions like RA, stimulate surrounding cells to secrete inflammatory mediators for damaging cartilage [106]. It has been shown that the use of exosomes derived from IL-10 treateddendritic cells, induced amelioration of RA severity [54]. IL-1 $\beta$-stimulated fibroblast-like synoviocytesderived EVs promoted osteoarthritic changes in chondrocytes [107]. In RA models, EVs have exhibited immunological abilities to induce apoptosis, presenting antigen to T cells, and causing extracellular damage [108]. All these pieces of evidence have contributed to propose synovium-derived EVs as possible biomarkers for RA [109, 110]; indeed, they might predict disease stage and, potentially, become relevant for building new and more effective therapeutic approaches.

The pathogenesis of RA may be related to the communication of EVs cell-to-cell, which involves many complex processes such as antigen presentation and formation of immune complexes [111], inflammation [112, 113], destruction of extracellular matrix [114], delivery of miRNAs [115, 116]. Withrow $\mathrm{J}$ et al. and $\mathrm{Fu} \mathrm{H}$ et al. reviewed in detail the research progress of EVs in these aspects [117, 118]. It can be concluded that EV mediates crosstalk between immune cells, synoviocytes, endothelial cells, and chondrocytes, thus affecting various processes of RA. These efforts may reveal the pathogenesis of RA, provide new insights into the targeted treatment of RA, and new treatment opportunities, as well as treatment strategies, may be discovered.

\section{Type 1 diabetes (TID)}

T1D, also called diabetes mellitus type 1 , is a form of diabetes mellitus in which pancreas fails to produce insulin. T1D is primarily a childhood associated autoimmune disease characterized by the destruction of insulin-producing $\beta$ cells in the pancreatic islets of Langerhans [119]. Recent work showed that EVs may be involved in the pathogenesis of T1D playing a role in the presentation of autoantigen peptides from insulin-producing $\beta$ cells. For example, $\mathrm{T}$ lymphocytes release exosomes containing specific microRNAs (for example, miR-142-3p, miR-142-5p, and miR-155) that transfer microRNAs to rodent and human pancreatic $\beta$ cells, these microRNAs triggers the expression of chemokines in pancreatic $\beta$ cells to promote apoptosis and result in insulin secretion disorders [120]. Exosomes also have shown potential as a therapeutic agent in treating T1D. In particular, exosomes from human urine-derived stem cells can prevent kidney injury in T1D rats by the transfer of growth factors, transforming growth factor- $\beta 1$, angiogenin and bone morphogenetic protein-7 [121]. Interestingly, studies of MSCs have consistently shown that MSCs can inhibit autoimmunity in T1D [122, 123]. More detailed research data later indicated the positive effect of EVs on these two autoimmune diseases [124]. MSC-derived EVs not only inhibits Th1 and Th17 cells but increases the expression of immunosuppressive cytokine IL-10, thereby effectively preventing T1D disease development [124]. To further characterize of exosomes, their underlying mechanisms and relationship with different stages of the disease will furnish the understanding of the role of exosomes in the pathogenesis of T1D and their possible application as therapeutic tools.

\section{Antiphospholipid syndrome (APS)}

APS is an autoimmune disease that can cause venous or arterial thromboembolism or severe pregnancy mortality [125]. In the last two decades, researchers have believed that the APS pathogenesis may be related to persistent antiphospholipid antibodies (aPL) [126], and the main difficulty in elucidating the pathogenesis of APS is the heterogeneity of aPL [127]. There is strong evidence that EVs in patients with APS are indeed elevated. It is speculated that elevated EVs levels reflect the general state of vascular activation. It has been reported that EVs may stimulate thrombosis and promote vascular activation [128]. Analysis conducted in sera of patients affected by APS reported a significant increase in endothelial cell-derived microvesicles [129]. Limited experimental data indicate that aPL stimulation can induce endothelial cells to release specific EVs, unlike normal types, which contain IL-1 $\beta$ and specific miRNA molecules. Thus, with the spread of such EVs, the unstimulated endothelial cell was activated by an autocrine or paracrine manner [130]. In the APS condition, EVs have shown to induce the development of thrombosis through several mechanisms. For example, microvesicles express a high level of phosphatidylserine [131], and this might facilitate the assembly of calcium-dependent coagulation complexes and supports thrombin generation. Further, EVs are, usually, enriched of tissue factors and may directly support procoagulant activity [132]. Recent evidence demonstrated that endothelial microvesicles can interact with blood monocytes and stimulate procoagulant activity [133]. 


\section{Systemic lupus erythematosus (SLE)}

SLE is a chronic systemic autoimmune disease that influences various organs and systems. SLE is featured by elevated levels of pathogenic autoantibodies, resulting in deposition of immune complexes that cause damage to multiple systems and organs [134, 135]. Several studies reported the defective of apoptosis activity in SLE, leading to the development of autoimmunity [136]. Moreover, SLE patients exhibit an increased level of IgG-MPs in plasma compared to controls and it correlates to dsDNA antibodies [137]. Recent evidence suggests that apoptosis-derived membrane vesicles from the serum of SLE patients may activate cyclic guanosine monophosphate (GMP)-AMP synthase (cGAS) and stimulator of interferon genes (STING) pathway to induce the production of IFN-I [138]. It is suggested that blocking the cGAS-STING pathway or inhibiting the secretion of apoptosis-derived membrane vesicles may be a promising therapeutic target for SLE. On the other hand, MSCs infusions technology has been used to treat a variety of diseases. Liu's team showed that MSCs infusions can improve bone loss in Fas-deficient MRL/lpr mice and restore the function of bone marrow-derived MSCs, the mechanism is that MSCs infusions can down-regulate the intracellular level of miR-29b by reusing Fas from MSCs infusions-derived exosomes, thereby restoring the hypomethylation of the Notch1 promoter in SLE patients, suggesting that exosomes may have clinical therapeutic value in saving SLE secondary osteoporosis [139].

\section{Hashimoto thyroiditis (HT)}

HT is a common autoimmune disease with an annual incidence rate of about 1 per 1,000 people, mainly affecting women [140]. The pathogenesis is complex and unknown. Etiology divides HT into primary and secondary forms [141]. The pathological features of HT are mainly infiltration of hematopoietic monocytes (mainly lymphocytes), destroying thyroid cells, causing thyroid enlargement, fibrosis or other variants [142-144]. Then clinical manifestations of thyroid function decline or even loss [145], causing abnormalities in the gastrointestinal system, cardiovascular system, lung system, hematopoietic system, and nervous system [141]. The current research status still cannot explain the pathogenesis of HT, and a recent work discussed whether circulating exosomes participate in the inflammatory response of HT. By detecting exosomes in the serum of patients, it is indicated that these exosomes present antigen to activate DCs, after activation, it leads to an imbalance of CD4+ T cell differentiation, may induce HT, or will become a breakthrough in the pathogenesis of HT [146].
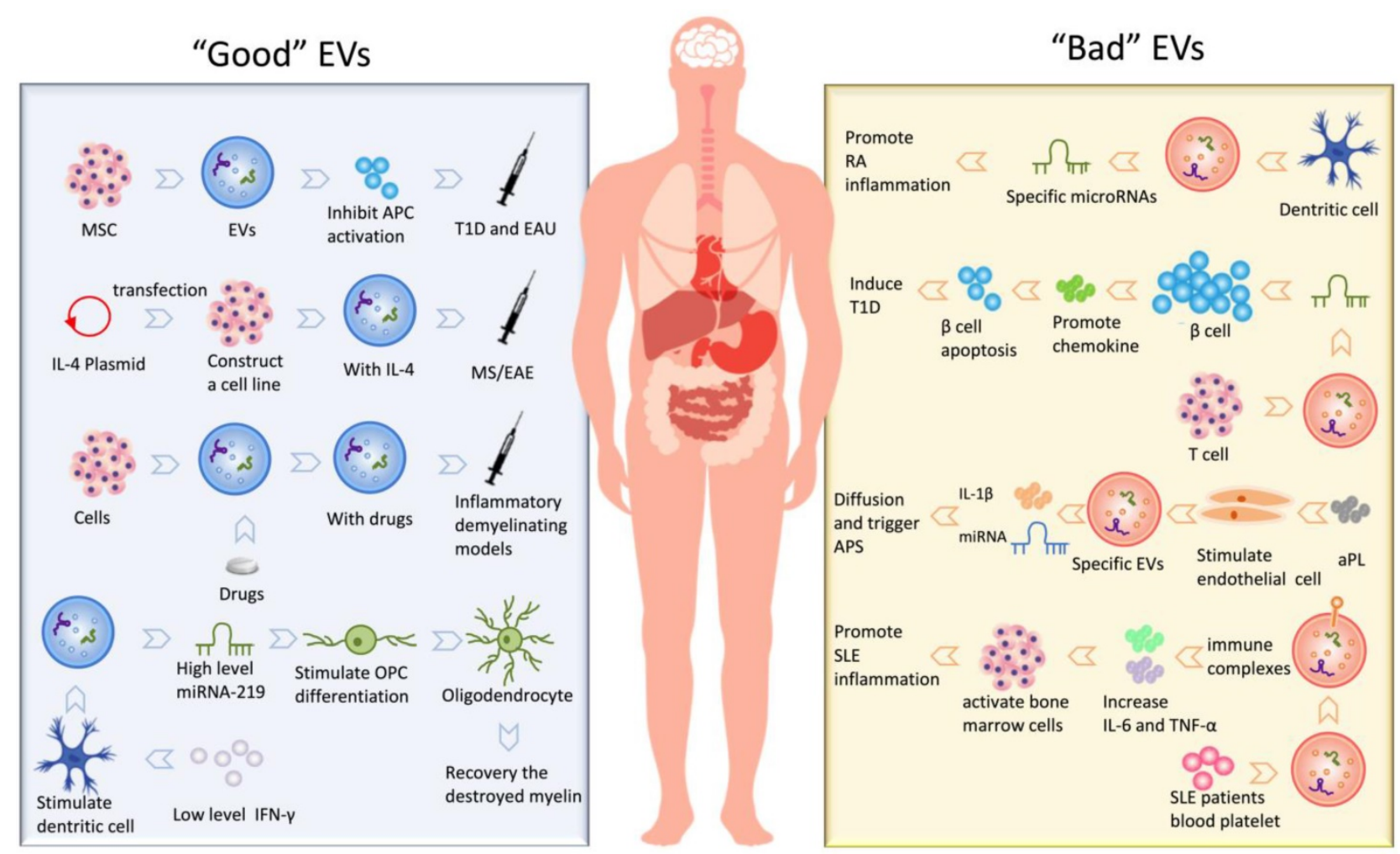

Figure 2. The application of extracellular vesicles in autoimmune diseases. 
In short, the existence of EVs is not only involved in the development of many autoimmune diseases but also participated in the treatment of these diseases as a therapeutic intermediary. We have summarized kinds of "Good" EVs that can participate in the treatment and "Bad" EVs that promote the development of the disease, shown in Fig. 2.

\section{Conclusion}

Research on EVs has been ardent since 2007 and has displayed unique advantages in various fields. EVs possess subcellular structures, which load and may deliver a variety of molecules that participate in many physiological processes. These pleiotropic effects may represent a greater breakthrough in the field of autoimmune diseases. However, the current problem to be solved is the standardization of the extraction and purification methods of EVs and the more accurate and effective quantification of the quantity or concentration of EVs. The characterization of EVs has been plaguing researchers, and the existing approaches are more or less flawed. With emerging technologies that can better solve this problem, spending more efforts to determine their origin characteristics, and the pathogenicity role of EVs may pave the way for new diagnostic methods. Given the various advantages of EVs and the current research results, we hope that EVs can also play a paramount role in autoimmune diseases, for example, as a carrier of therapeutic drugs or as a means of diagnosing diseases. This review retrospects the development, characterization, and biogenic derivation of EVs, as well as recent research achievements on autoimmune diseases. It is intended to provide basic ideas and information for scholars who have entered the field.

\section{Acknowledgments}

We thank Katherine Regan for editorial assistance. We apologize to all colleagues whose work could not be cited as a result of space limitations.

\section{Funding}

This study was supported by the Chinese National Natural Science Foundation (Grant Nos.31970771, 81771345), the Natural Science Foundation of Shaanxi Province, China (Grant Nos.2018JQ8033，2018JZ3001，2019KJXX-022), the Fundamental Research Funds for the Central Universities (Grant Nos. GK201903062, GK20182010, GK201701009, 2018CSLZ018), the Open Fund of Shanxi Key Laboratory of Inflammatory Neurodegenerative Diseases, Shanxi Datong University (Grant Nos.KF2019006, KF2019001).

\section{Competing Interests}

The authors have declared that no competing interest exists.

\section{References}

1. Raposo G, Stoorvogel W. Extracellular vesicles: exosomes, microvesicles, and friends. The Journal of cell biology. 2013; 200: 373-83.

2. Kalra H, Drummen GP, Mathivanan S. Focus on Extracellular Vesicles: Introducing the Next Small Big Thing. International journal of molecular sciences. 2016; 17: 170 .

3. Johnstone RM, Adam M, Hammond JR, Orr L, Turbide C. Vesicle formation during reticulocyte maturation. Association of plasma membrane activities with released vesicles (exosomes). The Journal of biological chemistry. 1987; 262: 9412-20.

4. Harding CV, Heuser JE, Stahl PD. Exosomes: looking back three decades and into the future. The Journal of cell biology. 2013; 200: 367-71.

5. Barile L, Vassalli G. Exosomes: Therapy delivery tools and biomarkers of diseases. Pharmacology \& therapeutics. 2017; 174: 63-78.

6. Morrison TJ, Jackson MV, Cunningham EK, Kissenpfennig A, McAuley DF, O'Kane CM, et al. Mesenchymal Stromal Cells Modulate Macrophages in Clinically Relevant Lung Injury Models by Extracellular Vesicle Mitochondrial Transfer. Am J Respir Crit Care Med. 2017; 196: 1275-86.

7. Meldolesi J. Extracellular vesicles, news about their role in immune cells: physiology, pathology and diseases. Clinical and experimental immunology. 2019; 196: 318-27.

8. Munagala R, Aqil F, Jeyabalan J, Gupta RC. Bovine milk-derived exosomes for drug delivery. Cancer letters. 2016; 371: 48-61.

9. Colombo M, Raposo G, Thery C. Biogenesis, secretion, and intercellular interactions of exosomes and other extracellular vesicles. Annual review of cell and developmental biology. 2014; 30: 255-89.

10. Vella LJ, Scicluna BJ. A rigorous method to enrich for exosomes from brain tissue. J Extracell Vesicles. 2017; 6: 1348885.

11. Ohno S, Drummen GP, Kuroda M. Focus on Extracellular Vesicles: Development of Extracellular Vesicle-Based Therapeutic Systems. International journal of molecular sciences. 2016; 17: 172.

12. Ha D, Yang N, Nadithe V. Exosomes as therapeutic drug carriers and delivery vehicles across biological membranes: current perspectives and future challenges. Acta pharmaceutica Sinica B. 2016; 6: 287-96.

13. Tian T, Zhang HX, He CP, Fan S, Zhu YL, Qi C, et al. Surface functionalized exosomes as targeted drug delivery vehicles for cerebral ischemia therapy. Biomaterials. 2018; 150: 137-49.

14. Zhuang X, Xiang X, Grizzle W, Sun D, Zhang S, Axtell RC, et al. Treatment of brain inflammatory diseases by delivering exosome encapsulated anti-inflammatory drugs from the nasal region to the brain. Molecular therapy : the journal of the American Society of Gene Therapy. 2011; 19: 1769-79.

15. Casella G, Colombo F, Finardi A, Descamps H, Ill-Raga G, Spinelli A, et al. Extracellular Vesicles Containing IL-4 Modulate Neuroinflammation in a Mouse Model of Multiple Sclerosis. Molecular Therapy. 2018; 26: 2107-18.

16. Turpin D, Truchetet ME, Faustin B, Augusto JF, Contin-Bordes C, Brisson A, et al. Role of extracellular vesicles in autoimmune diseases. Autoimmunity reviews. 2016; 15: 174-83.

17. Pfeffer SR. Two Rabs for exosome release. Nature cell biology. 2010; 12: 3-4.

18. Cocucci E, Racchetti G, Meldolesi J. Shedding microvesicles: artefacts no more. Trends in cell biology. 2009; 19: 43-51.

19. Hurley JH. ESCRT complexes and the biogenesis of multivesicular bodies. Current opinion in cell biology. 2008; 20: 4-11.

20. Hurley JH. The ESCRT complexes. Critical reviews in biochemistry and molecular biology. 2010; 45: 463-87.

21. Henne WM, Buchkovich NJ, Emr SD. The ESCRT pathway. Developmental cell. 2011; 21: 77-91.

22. Hurley JH, Hanson PI. Membrane budding and scission by the ESCRT machinery: it's all in the neck. Nature reviews Molecular cell biology. 2010; 11: 556-66.

23. Lorent JH, Levental I. Structural determinants of protein partitioning into ordered membrane domains and lipid rafts. Chemistry and physics of lipids. 2015; 192: 23-32.

24. Martin KR, Kantari-Mimoun C, Yin M, Pederzoli-Ribeil M, Angelot-Delettre F, Ceroi A, et al. Proteinase 3 Is a Phosphatidylserine-binding Protein That Affects the Production and Function of Microvesicles. The Journal of biological chemistry. 2016; 291: 10476-89.

25. Keerthikumar S, Chisanga D, Ariyaratne D, Al Saffar H, Anand S, Zhao K, et al. ExoCarta: A Web-Based Compendium of Exosomal Cargo. Journal of molecular biology. 2016; 428: 688-92.

26. Kowal J, Arras G, Colombo M, Jouve M, Morath JP, Primdal-Bengtson B, et al. Proteomic comparison defines novel markers to characterize heterogeneous populations of extracellular vesicle subtypes. Proc Natl Acad Sci U S A. 2016; 113: E968-77.

27. Yoshioka Y, Konishi Y, Kosaka N, Katsuda T, Kato T, Ochiya T. Comparative marker analysis of extracellular vesicles in different human cancer types. $\mathrm{J}$ Extracell Vesicles. 2013; 20424. 
28. Meldolesi J. Exosomes and Ectosomes in Intercellular Communication. Current biology : CB. 2018; 28: R435-r44

29. Sedgwick AE, D'Souza-Schorey $\mathrm{C}$. The biology of extracellular microvesicles. Traffic. 2018; 19: 319-27.

30. Buzas EI, Toth EA, Sodar BW, Szabo-Taylor KE. Molecular interactions at the surface of extracellular vesicles. Seminars in immunopathology. 2018; 40: 453-64.

31. Gardiner C, Di Vizio D, Sahoo S, Thery C, Witwer KW, Wauben M, et al. Techniques used for the isolation and characterization of extracellular vesicles: results of a worldwide survey. J Extracell Vesicles. 2016; 5: 32945.

32. Witwer KW, Soekmadji C. Updating the MISEV minimal requirements for extracellular vesicle studies: building bridges to reproducibility. J Extracell Vesicles. 2017; 6: 1396823.

33. Sun D, Zhuang X, Xiang X, Liu Y, Zhang S, Liu C, et al. A novel nanoparticle drug delivery system: the anti-inflammatory activity of curcumin is enhanced when encapsulated in exosomes. Molecular therapy : the journal of the American Society of Gene Therapy. 2010; 18: 1606-14.

34. Shao $\mathrm{H}, \mathrm{Im} \mathrm{H}$, Castro CM, Breakefield X, Weissleder R, Lee H. New Technologies for Analysis of Extracellular Vesicles. Chemical reviews. 2018; 118: 1917-50.

35. Kim MS, Haney MJ, Zhao Y, Yuan D, Deygen I, Klyachko NL, et al. Engineering macrophage-derived exosomes for targeted paclitaxel delivery to pulmonary metastases: in vitro and in vivo evaluations. Nanomedicine : nanotechnology, biology, and medicine. 2018; 14: 195-204.

36. Ludwig AK, De Miroschedji K, Doeppner TR, Borger V, Ruesing J, Rebmann $\mathrm{V}$, et al. Precipitation with polyethylene glycol followed by washing and pelleting by ultracentrifugation enriches extracellular vesicles from tissue culture supernatants in small and large scales. J Extracell Vesicles. 2018; 7: 1528109.

37. Wunsch BH, Smith JT, Gifford SM, Wang C, Brink M, Bruce RL, et al. Nanoscale lateral displacement arrays for the separation of exosomes and colloids down to $20 \mathrm{~nm}$. Nature nanotechnology. 2016; 11: 936-40.

38. Liu C, Xu X, Li B, Situ B, Pan W, Hu Y, et al. Single-Exosome-Counting Immunoassays for Cancer Diagnostics. Nano Lett. 2018; 18: 4226-32.

39. Wu M, Ouyang Y, Wang Z, Zhang R, Huang PH, Chen C, et al. Isolation of exosomes from whole blood by integrating acoustics and microfluidics. Proc Natl Acad Sci U S A. 2017; 114: 10584-9.

40. Kabe $\mathrm{Y}$, Suematsu M, Sakamoto S, Hirai M, Koike I, Hishiki T, et al Development of a Highly Sensitive Device for Counting the Number of Disease-Specific Exosomes in Human Sera. Clinical chemistry. 2018; 64: 1463-73.

41. Liu ML, Williams KJ, Werth VP. Microvesicles in Autoimmune Diseases. Advances in clinical chemistry. 2016; 77: 125-75.

42. Song Y, Zhang C, Zhang J, Jiao Z, Dong N, Wang G, et al. Localized injection of miRNA-21-enriched extracellular vesicles effectively restores cardiac function after myocardial infarction. Theranostics. 2019; 9: 2346-60.

43. Mondal A, Ashiq KA, Phulpagar P, Singh DK, Shiras A. Effective Visualization and Easy Tracking of Extracellular Vesicles in Glioma Cells. Biological procedures online. 2019; 21: 4

44. Roberts-Dalton HD, Cocks A, Falcon-Perez JM, Sayers EJ, Webber JP, Watson $\mathrm{P}$, et al. Fluorescence labelling of extracellular vesicles using a novel thiol-based strategy for quantitative analysis of cellular delivery and intracellular traffic. Nanoscale. 2017; 9: 13693-706.

45. Lazaro-Ibanez E, Neuvonen M. Metastatic state of parent cells influences the uptake and functionality of prostate cancer cell-derived extracellular vesicles. J Extracell Vesicles. 2017; 6: 1354645.

46. Paul D, Baena V, Ge S, Jiang X, Jellison ER, Kiprono T, et al. Appearance of claudin-5(+) leukocytes in the central nervous system during neuroinflammation: a novel role for endothelial-derived extracellular vesicles. Journal of neuroinflammation. 2016; 13: 292

47. Gupta MP, Tandalam S, Ostrager S, Lever AS, Fung AR, Hurley DD, et al. Non-reversible tissue fixation retains extracellular vesicles for in situ imaging. Nature methods. 2019; doi: 10.1038/s41592-019-0623-4.

48. Maas SL, de Vrij J, van der Vlist EJ, Geragousian B, van Bloois L, Mastrobattista E, et al. Possibilities and limitations of current technologies for quantification of biological extracellular vesicles and synthetic mimics. Journal of controlled release : official journal of the Controlled Release Society. 2015; 200: 87-96.

49. Gardiner C, Ferreira YJ, Dragovic RA, Redman CW, Sargent IL. Extracellular vesicle sizing and enumeration by nanoparticle tracking analysis. J Extracell Vesicles. 2013; 2. doi:10.3402/jev.v2i0.19671

50. Vogel R, Coumans FA, Maltesen RG, Böing AN, Bonnington KE, Broekman $\mathrm{ML}$, et al. A standardized method to determine the concentration of extracellular vesicles using tunable resistive pulse sensing. J Extracell Vesicles. 2016; 5: 31242

51. Akers JC, Ramakrishnan V, Nolan JP, Duggan E, Fu CC, Hochberg FH, et al. Comparative Analysis of Technologies for Quantifying Extracellular Vesicles (EVs) in Clinical Cerebrospinal Fluids (CSF). PloS one. 2016; 11: e0149866.

52. Stoner SA, Duggan E, Condello D, Guerrero A, Turk JR, Narayanan PK, et al. High sensitivity flow cytometry of membrane vesicles. Cytometry Part A : the journal of the International Society for Analytical Cytology. 2016; 89: 196-206.

53. Tian Y, Li S, Song J, Ji T, Zhu M, Anderson GJ, et al. A doxorubicin delivery platform using engineered natural membrane vesicle exosomes for targeted tumor therapy. Biomaterials. 2014; 35: 2383-90.
54. Kim SH, Lechman ER, Bianco N, Menon R, Keravala A, Nash J, et al. Exosomes derived from IL-10-treated dendritic cells can suppress inflammation and collagen-induced arthritis. Journal of immunology (Baltimore, Md : 1950). 2005; 174: 6440-8.

55. Kamerkar S, LeBleu VS, Sugimoto H, Yang S, Ruivo CF, Melo SA, et al. Exosomes facilitate therapeutic targeting of oncogenic KRAS in pancreatic cancer. Nature. 2017; 546: 498-503.

56. Najar M, Bouhtit F, Melki R, Afif H, Hamal A, Fahmi H, et al. Mesenchymal Stromal Cell-Based Therapy: New Perspectives and Challenges. Journal of clinical medicine. 2019; 8. doi:10.3390/jcm8050626

57. Carreras-Planella L, Monguio-Tortajada M, Borras FE, Franquesa M. Immunomodulatory Effect of MSC on B Cells Is Independent of Secreted Extracellular Vesicles. Frontiers in immunology. 2019; 10: 1288.

58. Fujii $S$, Miura $Y$. Graft-Versus-Host Disease Amelioration by Human Bone Marrow Mesenchymal Stromal/Stem Cell-Derived Extracellular Vesicles Is Associated with Peripheral Preservation of Naive T Cell Populations. Stem Cells. 2018; 36: 434-45.

59. Burrello I, Monticone S, Gai C, Gomez Y, Kholia S, Camussi G. Stem Cell-Derived Extracellular Vesicles and Immune-Modulation. Frontiers in cell and developmental biology. 2016; 4: 83.

60. Jia G, Han Y, An Y, Ding Y, He C, Wang X, et al. NRP-1 targeted and cargo-loaded exosomes facilitate simultaneous imaging and therapy of glioma in vitro and in vivo. Biomaterials. 2018; 178: 302-16.

61. Vader P, Mol EA, Pasterkamp G, Schiffelers RM. Extracellular vesicles for drug delivery. Advanced drug delivery reviews. 2016; 106: 148-56.

62. Kumar S, Michael IJ, Park J, Granick S, Cho YK. Cloaked Exosomes: Biocompatible, Durable, and Degradable Encapsulation. Small. 2018; 14: e1802052

63. Longatti A, Schindler C. High affinity single-chain variable fragments are specific and versatile targeting motifs for extracellular vesicles. Nanoscale. 2018; 10: 14230-44

64. Haney MJ, Klyachko NL, Zhao Y, Gupta R, Plotnikova EG, He Z, et al. Exosomes as drug delivery vehicles for Parkinson's disease therapy. Journal of controlled release : official journal of the Controlled Release Society. 2015; 207: $18-30$

65. Smyth T, Kullberg M, Malik N, Smith-Jones P, Graner MW, Anchordoquy TJ. Biodistribution and delivery efficiency of unmodified tumor-derived exosomes. Journal of controlled release : official journal of the Controlled Release Society. 2015; 199: 145-55.

66. Phinney DG, Pittenger MF. Concise Review: MSC-Derived Exosomes for Cell-Free Therapy. Stem Cells. 2017; 35: 851-8.

67. Piffoux M, Silva AKA, Wilhelm C. Modification of Extracellular Vesicles by Fusion with Liposomes for the Design of Personalized Biogenic Drug Delivery Systems. ACS Nano. 2018; 12: 6830-42.

68. Crossland RE, Norden J, Kralj Juric M, Pearce KF, Lendrem C, Bibby LA, et al. Serum and Extracellular Vesicle MicroRNAs miR-423, miR-199, and miR-93* As Biomarkers for Acute Graft-versus-Host Disease. Frontiers in immunology. 2017; 8: 1446.

69. Lia G, Brunello L, Bruno S, Carpanetto A, Omede P, Festuccia M, et al. Extracellular vesicles as potential biomarkers of acute graft-vs-host disease. Leukemia. 2018; 32: 765-73.

70. Wang L, Gu Z, Zhao X, Yang N, Wang F, Deng A, et al. Extracellular Vesicles Released from Human Umbilical Cord-Derived Mesenchymal Stromal Cells Prevent Life-Threatening Acute Graft-Versus-Host Disease in a Mouse Model of Allogeneic Hematopoietic Stem Cell Transplantation. Stem cells and development. 2016; 25: 1874-83.

71. Kordelas L, Rebmann V, Ludwig AK, Radtke S, Ruesing J, Doeppner TR, et al. MSC-derived exosomes: a novel tool to treat therapy-refractory graft-versus-host disease. Leukemia. 2014; 28: 970-3.

72. Chulpanova D, Kitaeva K, James V, Rizvanov A, Solovyeva V. Therapeutic Prospects of Extracellular Vesicles in Cancer Treatment. Frontiers in immunology. 2018; 9: 1534

73. Yang DZ, Liang J, Zhang F, Yao HB, Shu Y. Clinical effect of montelukast sodium combined with inhaled corticosteroids in the treatment of OSAS children. Medicine. 2017; 96: e6628.

74. Zhou Y, Ren H, Dai B, Li J, Shang L, Huang J, et al. Hepatocellular carcinoma-derived exosomal miRNA-21 contributes to tumor progression by converting hepatocyte stellate cells to cancer-associated fibroblasts. Journal of experimental \& clinical cancer research : CR. 2018; 37: 324.

75. Xu J, Wang Y, Hsu C, Gao Y, Meyers C, Chang L, et al. Human perivascular stem cell-derived extracellular vesicles mediate bone repair. eLife. 2019; 8: undefined. doi:10.7554/eLife.48191

76. Vonk L, Dooremalen Sv, Liv N, Klumperman J, Coffer P, Saris D, et al. Mesenchymal Stromal/stem Cell-derived Extracellular Vesicles Promote Human Cartilage Regeneration. Theranostics. 2018; 8: 906-20.

77. Verderio C, Muzio L, Turola E, Bergami A, Novellino L, Ruffini F, et al Myeloid microvesicles are a marker and therapeutic target for neuroinflammation. Annals of neurology. 2012; 72: 610-24.

78. Lee J, McKinney KQ Pavlopoulos AJ, Han $\mathrm{MH}$, Kim SH, Kim HJ, et al. Exosomal proteome analysis of cerebrospinal fluid detects biosignatures of neuromyelitis optica and multiple sclerosis. Clinica chimica acta; international ournal of clinical chemistry. 2016; 462: 118-26

79. Tominaga N, Yoshioka Y, Ochiya T. A novel platform for cancer therapy using extracellular vesicles. Advanced drug delivery reviews. 2015; 95: 50-5. 
80. Robbins PD, Morelli AE. Regulation of immune responses by extracellular vesicles. Nature reviews Immunology. 2014; 14: 195-208.

81. Loov C, Scherzer CR, Hyman BT, Breakefield XO, Ingelsson $\mathrm{M}$. alpha-Synuclein in Extracellular Vesicles: Functional Implications and Diagnostic Opportunities. Cellular and molecular neurobiology. 2016; 36: 437-48.

82. Huttner HB, Corbeil D, Thirmeyer C, Coras R, Kohrmann M, Mauer C, et al Increased membrane shedding--indicated by an elevation of CD133-enriched membrane particles--into the CSF in partial epilepsy. Epilepsy research. 2012; 99: 101-6.

83. Liu ML, Werth VP, Williams KJ. Blood plasma versus serum: which is right for sampling circulating membrane microvesicles in human subjects? Annals of the rheumatic diseases. 2019. doi:10.1136/annrheumdis-2019-215505

84. Kato Y, Park J, Takamatsu H, Kumanogoh A. Response to: 'Blood plasma versus serum: which is right for sampling circulating membrane microvesicles in human subjects?' by Liu et al. Annals of the rheumatic diseases. 2019. doi:10.1136/annrheumdis-2019-215540

85. Sole C, Cortes-Hernandez J, Felip ML, Vidal M, Ordi-Ros J. miR-29c in urinary exosomes as predictor of early renal fibrosis in lupus nephritis. Nephrology, dialysis, transplantation : official publication of the European Dialysis and Transplant Association - European Renal Association. 2015; 30: 1488-96.

86. Jagot F, Davoust N. Is It worth Considering Circulating microRNAs in Multiple Sclerosis? Frontiers in immunology. 2016; 7: 129.

87. Saenz-Cuesta $\mathrm{M}$, Irizar $\mathrm{H}$, Castillo-Trivino $\mathrm{T}$, Munoz-Culla $\mathrm{M}$, Osorio-Querejeta I, Prada A, et al. Circulating microparticles reflect treatment effects and clinical status in multiple sclerosis. Biomarkers in medicine. 2014; 8: 653-61.

88. Selmaj I, Cichalewska M, Namiecinska M, Galazka G, Horzelski W, Selmaj $\mathrm{KW}$, et al. Global exosome transcriptome profiling reveals biomarkers for multiple sclerosis. Annals of neurology. 2017; 81: 703-17.

89. Clayton A, Court J, Navabi H, Adams M, Mason MD, Hobot JA, et al. Analysis of antigen presenting cell derived exosomes, based on immuno-magnetic isolation and flow cytometry. Journal of immunological methods. 2001; 247: 163-74.

90. Arima Y, Liu W, Takahashi Y, Nishikawa M, Takakura Y. Effects of localization of antigen proteins in antigen-loaded exosomes on efficiency of antigen presentation. Molecular pharmaceutics. 2019; 16: 2309-14.

91. Leone DA, Rees AJ, Kain R. Dendritic cells and routing cargo into exosomes. Immunology \& Cell Biology. 2018; 96: 683-93.

92. Morelli AE, Larregina AT, Shufesky WJ, Sullivan ML, Stolz DB, Papworth GD, et al. Endocytosis, intracellular sorting, and processing of exosomes by dendritic cells. Blood. 2004; 104: 3257-66.

93. Liu Q, Rojas-Canales DM, Divito SJ, Shufesky WJ, Stolz DB, Erdos G, et al. Donor dendritic cell-derived exosomes promote allograft-targeting immune response. The Journal of clinical investigation. 2016; 126: 2805-20.

94. Thery C, Duban L, Segura E, Veron P, Lantz O, Amigorena S. Indirect activation of naive CD4+ T cells by dendritic cell-derived exosomes. Nature immunology. 2002; 3: 1156-62.

95. Aiello S, Rocchetta F, Longaretti L, Faravelli S, Todeschini M, Cassis L, et al. Extracellular vesicles derived from $\mathrm{T}$ regulatory cells suppress $\mathrm{T}$ cell proliferation and prolong allograft survival. Sci Rep. 2017; 7: 11518.

96. Okoye IS, Coomes SM, Pelly VS, Czieso S, Papayannopoulos V, Tolmachova T, et al. MicroRNA-containing T-regulatory-cell-derived exosomes suppress pathogenic T helper 1 cells. Immunity. 2014; 41: 89-103.

97. Njock MS, Cheng HS, Dang LT, Nazari-Jahantigh M, Lau AC, Boudreau E, et al. Endothelial cells suppress monocyte activation through secretion of extracellular vesicles containing antiinflammatory microRNAs. Blood. 2015; 125: 3202-12.

98. Casado JG, Blazquez R, Vela FJ, Alvarez V, Tarazona R, Sanchez-Margallo FM. Mesenchymal Stem Cell-Derived Exosomes: Immunomodulatory Evaluation in an Antigen-Induced Synovitis Porcine Model. Frontiers in veterinary science. 2017; $4: 39$

99. Pistoia V, Raffaghello L. Mesenchymal stromal cells and autoimmunity. International immunology. 2017; 29: 49-58

100. Zhang Y, Han JJ, Liang XY, Zhao L, Zhang F, Rasouli J, et al. miR-23b Suppresses Leukocyte Migration and Pathogenesis of Experimental Autoimmune Encephalomyelitis by Targeting CCL7. Molecular therapy : the journal of the American Society of Gene Therapy. 2018; 26: 582-92

101. Li X, Zhang Y, Yan Y, Ciric B, Ma CG, Chin J, et al. LINGO-1-Fc-Transduced Neural Stem Cells Are Effective Therapy for Chronic Stage Experimental Autoimmune Encephalomyelitis. Molecular neurobiology. 2017; 54: 4365-78.

102. Selmaj I, Mycko MP, Raine CS, Selmaj KW. The role of exosomes in CNS inflammation and their involvement in multiple sclerosis. Journal of neuroimmunology. 2017; 306: 1-10.

103. Riazifar M, Mohammadi MR. Stem Cell-Derived Exosomes as Nanotherapeutics for Autoimmune and Neurodegenerative Disorders. ACS Nano. 2019; 13: 6670-88.

104. Yu L, Yang F, Jiang L, Chen Y, Wang K, Xu F, et al. Exosomes with membrane-associated TGF-beta1 from gene-modified dendritic cells inhibit murine EAE independently of MHC restriction. European journal of immunology. 2013; 43: 2461-72.

105. Pusic AD, Pusic KM, Kraig RP. What are exosomes and how can they be used in multiple sclerosis therapy? Expert review of neurotherapeutics. 2014; 14 : 353-5.
106. Lo Cicero A, Majkowska I, Nagase H, Di Liegro I, Troeberg L. Microvesicles shed by oligodendroglioma cells and rheumatoid synovial fibroblasts contain aggrecanase activity. Matrix biology : journal of the International Society for Matrix Biology. 2012; 31: 229-33.

107. Kato T, Miyaki S, Ishitobi H, Nakamura Y, Nakasa T, Lotz MK, et al. Exosomes from IL-1beta stimulated synovial fibroblasts induce osteoarthritic changes in articular chondrocytes. Arthritis research \& therapy. 2014; 16: R163.

108. Zhang HG, Liu C, Su K, Yu S, Zhang L, Zhang S, et al. A membrane form of TNF-alpha presented by exosomes delays T cell activation-induced cell death. Journal of immunology (Baltimore, Md : 1950). 2006; 176: 7385-93.

109. Skriner K, Adolph K, Jungblut PR, Burmester GR. Association of citrullinated proteins with synovial exosomes. Arthritis and rheumatism. 2006; 54: 3809-14.

110. Sellam J, Proulle V, Jungel A, Ittah M, Miceli Richard C, Gottenberg JE, et al. Increased levels of circulating microparticles in primary Sjogren's syndrome, systemic lupus erythematosus and rheumatoid arthritis and relation with disease activity. Arthritis research \& therapy. 2009; 11: R156.

111. Cloutier N, Tan S, Boudreau LH, Cramb C, Subbaiah R, Lahey L, et al. The exposure of autoantigens by microparticles underlies the formation of potent inflammatory components: the microparticle-associated immune complexes. EMBO molecular medicine. 2013; 5: 235-49.

112. Boilard E, Nigrovic PA, Larabee K, Watts GF, Coblyn JS, Weinblatt ME, et al. Platelets amplify inflammation in arthritis via collagen-dependent microparticle production. Science (New York, NY). 2010; 327: 580-3.

113. Headland SE, Jones HR, Norling LV, Kim A, Souza PR, Corsiero E, et al. Neutrophil-derived microvesicles enter cartilage and protect the joint in inflammatory arthritis. Science translational medicine. 2015; 7: 315ra190.

114. van Nieuwenhuijze AE, van de Loo FA, Walgreen B, Bennink M, Helsen M, van den Bersselaar $\mathrm{L}$, et al. Complementary action of granulocyte macrophage colony-stimulating factor and interleukin-17A induces interleukin-23, receptor activator of nuclear factor- $\mathrm{kB}$ ligand, and matrix metalloproteinases and drives bone and cartilage pathology in experimental arthritis: rationale for combination therapy in rheumatoid arthritis. Arthritis research \& therapy. 2015; $17: 163$.

115. Kurowska-Stolarska M, Alivernini S, Ballantine LE, Asquith DL, Millar NL, Gilchrist DS, et al. MicroRNA-155 as a proinflammatory regulator in clinical and experimental arthritis. Proc Natl Acad Sci U S A. 2011; 108: 11193-8.

116. Alexander M, Hu R, Runtsch MC, Kagele DA, Mosbruger TL, Tolmachova T, et al. Exosome-delivered microRNAs modulate the inflammatory response to endotoxin. Nature communications. 2015; 6: 7321.

117. Withrow J, Murphy C, Liu Y, Hunter M, Fulzele S, Hamrick MW. Extracellular vesicles in the pathogenesis of rheumatoid arthritis and osteoarthritis. Arthritis research \& therapy. 2016; 18: 286.

118. Fu H, Hu D, Zhang L, Tang P. Role of extracellular vesicles in rheumatoid arthritis. Molecular immunology. 2018; 93: 125-32.

119. Garcia-Contreras M, Brooks RW, Boccuzzi L, Robbins PD, Ricordi C. Exosomes as biomarkers and therapeutic tools for type 1 diabetes mellitus. European review for medical and pharmacological sciences. 2017; 21: 2940-56.

120. Guay C, Kruit JK, Rome S, Menoud V, Mulder NL, Jurdzinski A, et al. Lymphocyte-Derived Exosomal MicroRNAs Promote Pancreatic beta Cell Death and May Contribute to Type 1 Diabetes Development. Cell metabolism. 2018; 29: 348-61.

121. Jiang ZZ, Liu YM, Niu X, Yin JY, Hu B, Guo SC, et al. Exosomes secreted by human urine-derived stem cells could prevent kidney complications from type I diabetes in rats. Stem cell research \& therapy. 2016; 7: 24.

122. Kota DJ, Wiggins LL, Yoon N, Lee RH. TSG-6 produced by hMSCs delays the onset of autoimmune diabetes by suppressing Th1 development and enhancing tolerogenicity. Diabetes. 2013; 62: 2048-58.

123. Ko JH, Lee HJ, Jeong HJ, Kim MK, Wee WR, Yoon SO, et al. Mesenchymal stem/stromal cells precondition lung monocytes/macrophages to produce tolerance against allo- and autoimmunity in the eye. Proc Natl Acad Sci U S A. 2016; 113: 158-63.

124. Shigemoto-Kuroda T, Oh J, Kim D, Jeong H, Park S, Lee H, et al. MSC-derived Extracellular Vesicles Attenuate Immune Responses in Two Autoimmune Murine Models: Type 1 Diabetes and Uveoretinitis. Stem cell reports. 2017; 8: 1214-25.

125. Miyakis S, Lockshin MD, Atsumi T, Branch DW, Brey RL, Cervera R, et al. International consensus statement on an update of the classification criteria for definite antiphospholipid syndrome (APS). Journal of thrombosis and haemostasis : JTH. 2006; 4: 295-306.

126. Pierangeli SS, Barker JH, Stikovac D, Ackerman D, Anderson G, Barquinero J, et al. Effect of human IgG antiphospholipid antibodies on an in vivo thrombosis model in mice. Thrombosis and haemostasis. 1994; 71: 670-4.

127. Lackner KJ, Muller-Calleja N. Pathogenesis of antiphospholipid syndrome: recent insights and emerging concepts. Expert review of clinical immunology. 2018; 15: 199-209.

128. Zara M, Guidetti GF, Camera M, Canobbio I, Amadio P, Torti M, et al. Biology and Role of Extracellular Vesicles (EVs) in the Pathogenesis of Thrombosis. International journal of molecular sciences. 2019; 20. doi:10.3390/ijms20112840

129. Combes V Simon AC Grau GE Arnoux D Camoin L Sabatier $F$ et al. In vitro generation of endothelial microparticles and possible prothrombotic activity in patients with lupus anticoagulant. The Journal of clinical investigation. 1999; 104: 93-102.

130. Wu M, Barnard J, Kundu S, McCrae KR. A novel pathway of cellular activation mediated by antiphospholipid antibody-induced extracellular vesicles. Journal of thrombosis and haemostasis : JTH. 2015; 13: 1928-40. 
131. Leroyer AS, Anfosso F, Lacroix R, Sabatier F, Simoncini S, Njock SM, et al. Endothelial-derived microparticles: Biological conveyors at the crossroad of inflammation, thrombosis and angiogenesis. Thrombosis and haemostasis. 2010; 104: 456-63.

132. Thomas GM, Brill A, Mezouar S, Crescence L, Gallant M, Dubois C, et al. Tissue factor expressed by circulating cancer cell-derived microparticles drastically increases the incidence of deep vein thrombosis in mice. Journal of thrombosis and haemostasis : JTH. 2015; 13: 1310-9.

133. Sabatier F, Roux V, Anfosso F, Camoin L, Sampol J, Dignat-George F. Interaction of endothelial microparticles with monocytic cells in vitro induces tissue factor-dependent procoagulant activity. Blood. 2002; 99: 3962-70.

134. Colasanti T, Maselli A, Conti F, Sanchez M, Alessandri C, Barbati C, et al. Autoantibodies to estrogen receptor alpha interfere with $\mathrm{T}$ lymphocyte homeostasis and are associated with disease activity in systemic lupus erythematosus. Arthritis and rheumatism. 2012; 64: 778-87.

135. Al-Shobaili HA, Al Robaee AA, Alzolibani AA, Rasheed Z. Antibodies against 4-hydroxy-2-nonenal modified epitopes recognized chromatin and its oxidized forms: role of chromatin, oxidized forms of chromatin and 4-hydroxy-2-nonenal modified epitopes in the etiopathogenesis of SLE. Disease markers. 2012; 33: 19-34.

136. Dieker J, Hilbrands L, Thielen A, Dijkman H, Berden JH, van der Vlag J. Enhanced activation of dendritic cells by autologous apoptotic microvesicles in MRL/lpr mice. Arthritis research \& therapy. 2015; 17: 103.

137. Nielsen CT, Ostergaard O, Stener L, Iversen LV, Truedsson L, Gullstrand B, et al. Increased IgG on cell-derived plasma microparticles in systemic lupus erythematosus is associated with autoantibodies and complement activation. Arthritis and rheumatism. 2012; 64: 1227-36.

138. Kato Y, Park J, Takamatsu H, Konaka H, Aoki W, Aburaya S, et al. Apoptosis-derived membrane vesicles drive the cGAS-STING pathway and enhance type I IFN production in systemic lupus erythematosus. Annals of the rheumatic diseases. 2018; 77: 1507-15.

139. Liu S, Liu D, Chen C, Hamamura K, Moshaverinia A, Yang R, et al. MSC Transplantation Improves Osteopenia via Epigenetic Regulation of Notch Signaling in Lupus. Cell metabolism. 2015; 22: 606-18.

140. McLeod DS, Cooper DS. The incidence and prevalence of thyroid autoimmunity. Endocrine. 2012; 42: 252-65.

141. Caturegli P, De Remigis A, Rose NR. Hashimoto thyroiditis: clinical and diagnostic criteria. Autoimmunity reviews. 2014; 13: 391-7.

142. De Luca F, Santucci S, Corica D, Pitrolo E, Romeo M, Aversa T. Hashimoto's thyroiditis in childhood: presentation modes and evolution over time. Italian journal of pediatrics. 2013; 39: 8 .

143. Li Y, Bai Y, Liu Z, Ozaki T, Taniguchi E, Mori I, et al. Immunohistochemistry of IgG4 can help subclassify Hashimoto's autoimmune thyroiditis. Pathology international. 2009; 59: 636-41.

144. Caturegli P, De Remigis A, Chuang K, Dembele M, Iwama A, Iwama S. Hashimoto's thyroiditis: celebrating the centennial through the lens of the Johns Hopkins hospital surgical pathology records. Thyroid : official journal of the American Thyroid Association. 2013; 23: 142-50.

145. Vanderpump MP. The epidemiology of thyroid disease. British medical bulletin. 2011; 99: 39-51.

146. Cui X, Liu Y, Wang S, Zhao N, Qin J, Li Y, et al. Circulating Exosomes Activate Dendritic Cells and Induce Unbalanced CD4+ $\mathrm{T}$ Cell Differentiation in Hashimoto Thyroiditis. The Journal of clinical endocrinology and metabolism. 2019; 104: 4607-18.

147. Lee JY, Park JK, Lee EY, Lee EB, Song YW. Circulating exosomes from patients with systemic lupus erythematosus induce an proinflammatory immune response. Arthritis research \& therapy. 2016; 18: 264.

148. Perez-Hernandez J, Forner MJ, Pinto C, Chaves FJ, Cortes R, Redon J. Increased Urinary Exosomal MicroRNAs in Patients with Systemic Lupus Erythematosus. PloS one. 2015; 10: e0138618.

149. Rahman MJ, Regn D, Bashratyan R, Dai YD. Exosomes released by islet-derived mesenchymal stem cells trigger autoimmune responses in NOD mice. Diabetes. 2014; 63: 1008-20.

150. Song J, Kim D, Han J, Kim Y, Lee M, Jin EJ. PBMC and exosome-derived Hotair is a critical regulator and potent marker for rheumatoid arthritis. Clinical and experimental medicine. 2015; 15: 121-6.

151. Michael A, Bajracharya SD, Yuen PS, Zhou H, Star RA, Illei GG, et al. Exosomes from human saliva as a source of microRNA biomarkers. Oral diseases. 2010; 16: 34-8

152. Mazzeo C, Canas JA, Zafra MP, Rojas Marco A, Fernandez-Nieto M, Sanz V, et al. Exosome secretion by eosinophils: A possible role in asthma pathogenesis. The Journal of allergy and clinical immunology. 2015; 135: 1603-13.

153. Pieragostino D, Cicalini I, Lanuti P, Ercolino E, di Ioia M, Zucchelli M, et al. Enhanced release of acid sphingomyelinase-enriched exosomes generates a lipidomics signature in CSF of Multiple Sclerosis patients. Sci Rep. 2018; 8: 3071.

154. Galazka G, Mycko MP, Selmaj I, Raine CS, Selmaj KW. Multiple sclerosis: Serum-derived exosomes express myelin proteins. Multiple sclerosis. 2018; 24 : 449-58.

155. Lytvyn Y, Xiao F, Kennedy CR, Perkins BA, Reich HN, Scholey JW, et al. Assessment of urinary microparticles in normotensive patients with type 1 diabetes. Diabetologia. 2017; 60: 581-4. 